\title{
ANALISIS HABITAT Alpinia eremochlamys K.Schum. DI HUTAN PEGUNUNGAN SEKITAR DANAU KALIMPA'A TAMAN NASIONAL LORE LINDU, SULAWESI TENGAH
}

\section{Analysis Habitat Of Alpinia Eremochlamys K.Schum. In The Mountain Forest Around Kalimpa'a Lake, Lore Lindu National Park Central Sulawesi}

\author{
Stefani Tamawiwi ${ }^{*}$, Moh. Iqbal, Ramadanil \\ Jurusan Biologi Fakultas Matematika dan Ilmu Pengetahuan Alam Universitas Tadulako Tondo \\ Palu, Sulawesi Tengah 94118
}

Keywords:

Alpinia

eremochlamys

K.Schum.,

vegetation

analysis, Lake

Kalimpa'a

Kata Kunci:

Alpinia

eremochlamys

K.Schum., Analisis vegetasi, Danau

Kalimpa'a

\begin{abstract}
The research "vegetation analysis of Alpinia Eremochlamys K.Schum. Habitat in the mountain forest around Kalimpa'a lake, Lore Lindu National Park Central Sulawesi" has been conducted from August to November 2018. The objective of the research was investigate species in the habitat of Alpinia Eremochlamys K.Schum. and to measure enviromental condition. The research was used multiple plots method, where plots were observed sistematicaly. The results indicated that the vegetation at tree level dominated by Mallotus paniculatus Mull.Arg., a pole level was dominated by Elaeocarpussphaericus, vegetation of sapling by Vaccinium sp. and seeding level was dominated by Ageratum conyzoides L. The daily average temperature was $22.38^{\circ} \mathrm{C}$, relative humidity was $70.16 \%$ and light intensity average of 387.3 lux.
\end{abstract}

\begin{abstract}
ABSTRAK
Penelitian "Analisis Vegetasi habitat Alpinia eremochlamys K.Schum. di hutan pegunungan sekitar danau Kalimpa'a Taman Nasional Lore Lindu Sulawesi Tengah" telah dilaksanakan dari bulan Agustus sampai November 2018. Penelitian bertujuan untuk mengetahui jenis vegetasi habitat Alpinia eremochlamys K.Schum. di hutan pegunungan sekitar Danau Kalimpa'a Taman Nasional Lore Lindu Sulawesi Tengah. Penelitian menggunakan metode petak ganda yang diletakkan secara sistematis. Hasil penelitian menunjukan vegetasi pada tingkat pohon didominasi oleh Mallotus paniculatus Mull.Arg., tingkat tiang oleh Elaeocarpus sphaericus, tingkat pancang oleh Vaccinium sp. dan tingkat semai/tumbuhan bawah oleh Ageratum conyzoides L.Suhu harian rata-rata $22.38^{\circ} \mathrm{C}$, kelembaban relatif $70.16 \%$ dan intensitas cahaya rata-rata 387.3 lux.
\end{abstract}

Corresponding Author : stefanitamawiwi@gmail.com 


\section{PENDAHULUAN}

Sulawesi merupakan pulau terbesar yang terletak dalam subregion biogeografi Wallacea. Termasuk wilayah yang unik dan merupakan suatu kawasan peralihan antara Benua Asia dan Australia yang memiliki keanekaragaman hayati di berbagai kawasan koservasi seperti Taman Nasional, Suaka Margasatwa dan Cagar Alam dengan tingkat endemisitas yang cukup tinggi (Pitopang dkk., 2011).

Jenis tumbuhan yang telah dikoleksi dari Pulau Sulawesi diantaranya adalah jenisjenis tumbuhan herbadari famili Zingiberaceae (jahe-jahean). Zingiberaceae dikenal sebagai kelompok temu-temuan oleh masyarakat Indonesia, yang merupakan tanaman multiguna dibudidayakan dan dikembangkan baik sebagai tanaman hias, maupun sebagai tanaman obat. Anggota dari famili ini masih memiliki kerabat liar yang hidup di hutan tropis Indonesia (Lee et al.,2001). Salah satu jenis tumbuhan dari famili Zingiberaceae adalah Alpinia eremochlamys K.Schum.yang merupakan salah satu tumbuhan yang memiliki area sebaran di Sulawesi. Tumbuhan ini memiliki tinggi 2-3 m. Hidup berkelompok atau berumpun (Santika, 2015).

Habitat tumbuhan Alpinia eremochlamys K.Schum. banyak terdapat di hutan pegunungan sekitar Danau Kalimpa'a Taman Nasional Lore Lindu. Lore Lindu merupakan salah satu Taman Nasional di Indonesia yang memiliki kawasan konservasi terbesar yang terdapat di Provinsi Sulawesi Tengah dengan luas $229.177,5$ ha. Taman Nasional ini memiliki beranekaragam jenis hayati dan merupakan salah satu dari 10 hotspot keanekaragaman hayati yang unik di dunia. Taman Nasional Lore Lindu telah mendapat banyak predikat atau julukan karena potensi dan keunikan yang dimilikinya, diantaranya adalah sebagai cagar biosfer pada tahun 1977 oleh MABUNESCO (Pitopang, 2012).

Danau Kalimpa'a atau sering disebut Danau Tambing adalah objek wisata alam di kawasan Taman Nasional Lore Lindu dan berada dalam wilayah Pengelolaan Taman Nasional Lore Lindu Wilayah III Poso. Disekitarnya terdapat hutan tropis yang masih cukup baik dan alami (Kementrian Lingkungan Hidup dan Kehutanan, 2015). Jenis vegetasi disekitar habitat Alpinia eremochlamys K.Schum. belum banyak diinformasikan.

Berdasarkan hal tersebut, perlu dilakukan penelitian tentang Analisis Vegetasi padahabitat Alpinia eremochlamys K.Schum. (Zingiberaceae) untuk menambah data ekologi di Sulawesi, khususnya di Taman Nasional Lore Lindu. 


\section{BAHAN DAN METODE}

Alat-alatyang digunakan yaitu GPS (Global Positioning System) untuk menentukan titik koordinat geografis, Thermohygrometer untuk mengukur kelembaban udara dan suhu udara, Luxmeter untuk mengukur intensitas cahaya dan Soil Tester untuk mengukur $\mathrm{pH}$ tanah serta kelembaban tanah, gunting stek untuk mengambil sampel tumbuhan, sasak untuk merapikan sampel, buku lapangan untuk mencatat data, kamera untuk memotret bagianbagian yang diamati serta untuk mendokumentasi proses penelitian, meteran untuk mengukur panjang dan lebar plot.Bahanyang digunakan yaitu spritus untuk mengawetkan sampel, label gantung untuk menandai sampel, koran untuk membuat spesimen herbarium, plastik sampel untuk tempat spesimen herbarium dan tali rafiah untuk membuat plot.

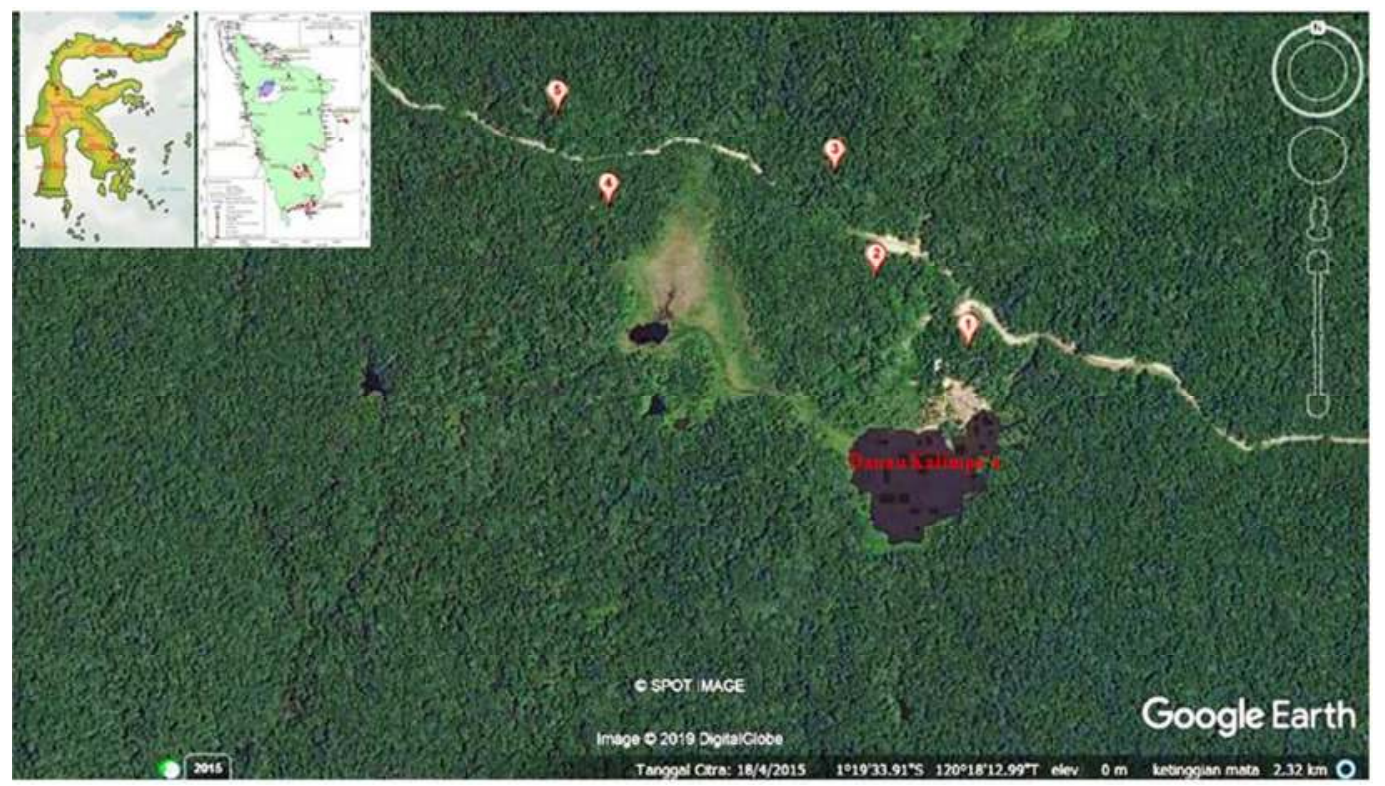

Gambar 1. Peta lokasi penelitian; Sumber : Google Earth

\section{Prosedur Kerja}

Metode yang digunakan adalah metodesurveydengan penentuan plot secara sengaja (purposive sampling) degan ukuran $20 \mathrm{~m} \times 20 \mathrm{~m}$ untuk tingkat pohon, $10 \mathrm{~m} \times 10 \mathrm{~m}$ untuk tingkat tiang, $5 \mathrm{~m} \times 5 \mathrm{~m}$ untuk tingkat pancang dan $2 \mathrm{~m} \times 2 \mathrm{~m}$ untuk tingkat semai. Plot pengamatan di buat sebanyak 5 plot disekitar lokasi penelitian pada habitat Alpinia eremochlamys K.Schum. 
Tabel 1 Posisi geografi lokasi penelitian

\begin{tabular}{|c|c|c|c|}
\hline No. & Plot & Titik koordinat & $\begin{array}{l}\text { Ketinggian } \\
\text { m (dpl) }\end{array}$ \\
\hline 1 & I & $\begin{array}{l}01^{\circ} 19^{\prime} 30.72, \mathrm{~S} \\
120^{\circ} 18^{\prime} 31.2, \mathrm{E}\end{array}$ & 1721 \\
\hline 2 & II & $\begin{array}{l}\text { 01'19'25.90"S, } \\
\text { 120'18'25.3"E }\end{array}$ & 1743 \\
\hline 3 & III & $\begin{array}{l}\text { 01'19'18.70"S, } \\
\text { 12018'22.72"E }\end{array}$ & 1750 \\
\hline 4 & IV & $\begin{array}{l}01^{\circ} 19^{\prime} 13.30^{\prime \prime} \mathrm{S}, \\
120^{\circ} 17^{\prime} 52.222^{\prime \prime E}\end{array}$ & 1699 \\
\hline 5 & V & $\begin{array}{l}\text { 01'19'14.25"S, } \\
\text { 120'18'04.02"E }\end{array}$ & 1628 \\
\hline
\end{tabular}

Gambar 2. Bentuk dan ukuran petak contoh

Kriteria untuk menentukan tingkat pohon, tiang, pancang dan semai digunakan kriteria scara umum (Lamanimpa, 2007), yaitu:

1. Petak contoh berukuran $20 \times 20 \mathrm{~m}$ digunakan untuk tingkat pohon (diameter $>20 \mathrm{~cm}$ ).

2. Petak contoh berukuran $10 \times 10 \mathrm{~m}$ digunakan untuk tingkat tiang (diameter pohon 10-20 cm).

3. Petak contoh berukuran $5 \times 5 \mathrm{~m}$ digunakan untuk tingkat pancang (diameter pohon diameter $<10 \mathrm{~cm}$, tinggi $>1,5 \mathrm{~m}$ ).

4. Petak contoh berukuran $2 \times 2 \mathrm{~m}$ digunakan untuk tingkat semai dan tumbuhan bawah (tinggi tumbuhan $<1,5 \mathrm{~m})$.
$20 \mathrm{~m}$

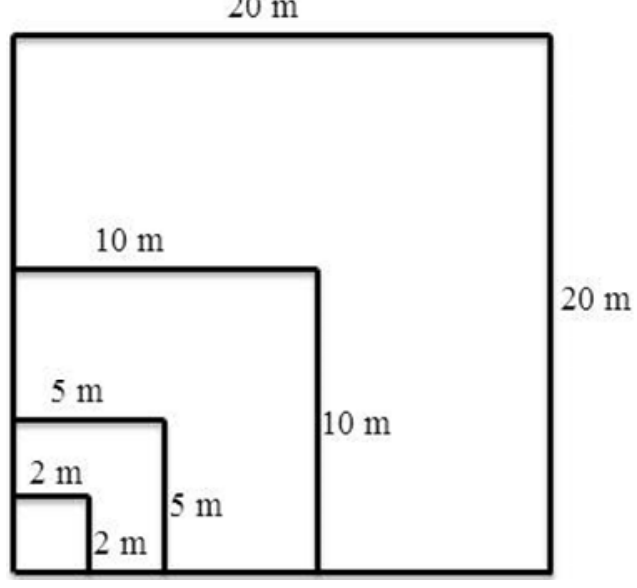

\section{Analisis Data}

Data vegetasi dianalisis dengan menggunakan rumus perhitungan analisa vegetasi menurut Dumbois-Muller dan Ellenberg (Soerianegara dan Indrawan, 1993), sebagai berikut:

- $\quad \operatorname{Kerapatan}(\mathrm{K})$ :

$\mathrm{K}=\frac{\text { Jumlah individu }}{\text { Luas total petak }}$

- $\quad$ Kerapatan Relatif (KR):

$\mathrm{KR}=\frac{\text { Kerapatan suatu Jenis }}{\text { Kerapatan total semua jenis }} \times 100 \%$

- $\quad$ Frekuensi(F):

$\mathrm{F}=\frac{\text { Jumlah petak ditempat individu }}{\text { Luas total petak }}$

- $\quad$ Frekuensi Relatif (FR):

$\mathrm{FR}=\frac{\text { Frekuensi suatu jenis }}{\text { Frekuensi total semua jenis }} \times 100 \%$

- Luas bidang dasar:

$\frac{1}{4} \cdot \pi \cdot d^{2}$

- Dominansi (D) :

$\mathrm{D}=\frac{\text { Luas bidang dasar suatu jenis }}{\text { Luas total petak }}$

- $\quad$ Dominansi Relatif (DR): 
$\mathrm{DR}=\frac{\text { Dominansi suatu jenis }}{\text { Dominansi total semua jenis }} \times 100 \%$

- $\quad$ Indeks keanekaragaman jenis $\left(\mathrm{H}^{\prime}\right)$ :

- $\quad$ Indeks Nilai Penting (INP) :

$\mathrm{KR}+\mathrm{FR}+\mathrm{DR}$ (Pohon, tiang dan pancang)

$$
\mathrm{H}^{\prime}=-\sum_{\mathrm{i}=1}^{\mathrm{n}}\left[\frac{n i}{N} \ln \frac{n i}{N}\right]
$$

$\mathrm{KR}+\mathrm{FR}$ (semai)

\section{HASIL}

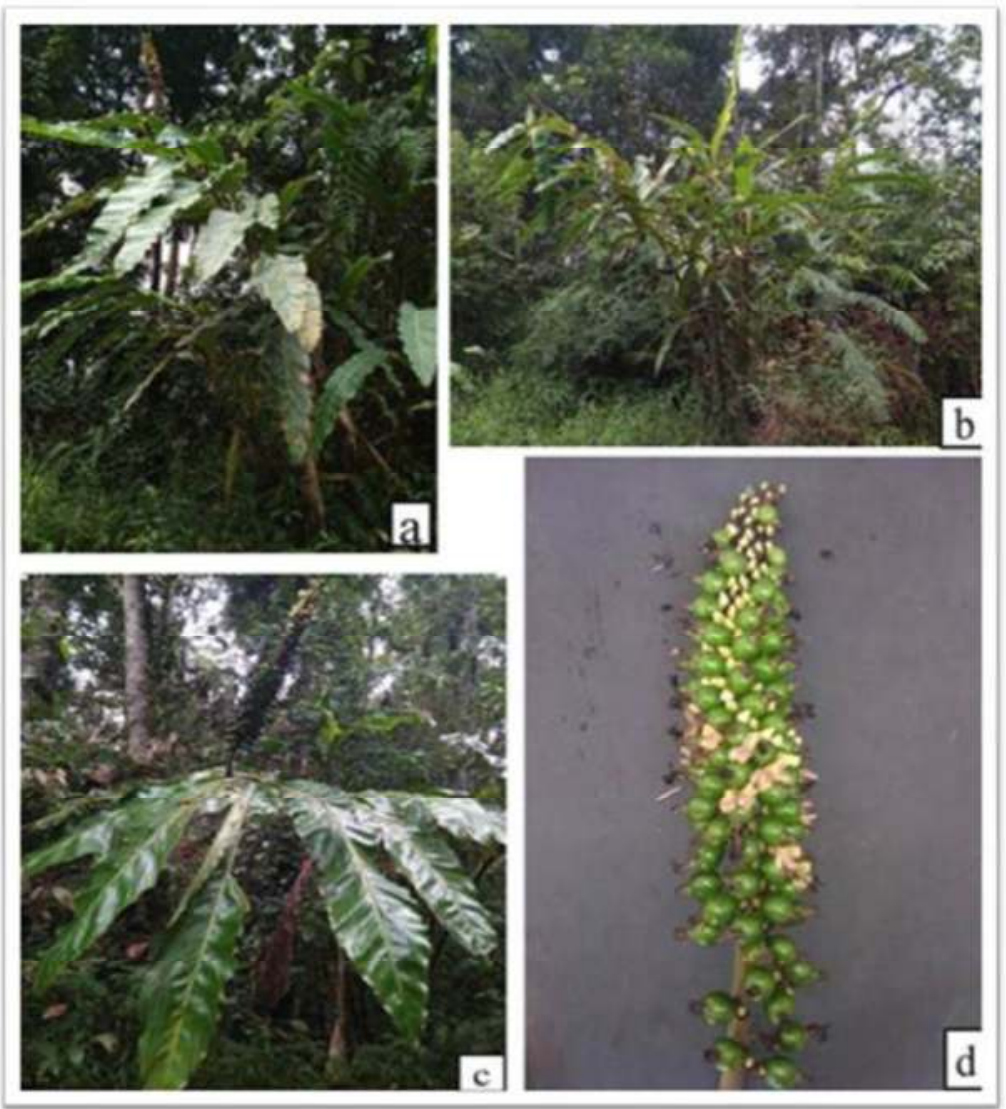

Gambar 3. Deskripsi Alpinia eremochlamys K.Schum. (a) dan (b) perawakan A. eremochlamys K.Schum.( c) daun A. eremochlamys K.Schum. (d) buah A. eremochlamys K.Schum

Deskripsi Alpinia eremochlamys dengan batang yang tegak dan tersusun dari

\section{K.Schum.}

Tumbuhan Alpinia eremochlamys K.Schum. merupakan tumbuhan herba hidup berkelompok atau berumpun, terdapat 3-5 dalam satu rumpun. Hidup di tanh liat berpasir dan berbatu. Tumbuhan ini memiliki perawakan dengan tinggi hingga $5 \mathrm{~m}$, pelepah-pelepah daun yang bersatu membentuk batang semu dan berwarna cokelat. Termasuk daun tunggal berwarna hijau dengan panjang daun 1-1,5 m dan lebar daun 20-30 cm, permukaan daun licin mengkilap serta ujung daun yang meruncing. Susunan daunnya berselang-seling, 
pertulangan daun menyirip, bentuk daun lanset memanjang, pangkal daun menumpul, tepian daun merata dan terdapat 8-10 jumlah daun dalam satu tangkai. Merupakan buah buni yang berbentuk bulat dan keras, berwarna hijau tua, berdiameter $1,7 \mathrm{~cm}$, dalam satu tangkai anak buah terdapat dua bulir namun hanya satu yang menjadi buah, serta terdapat $50-80$ buah dalam satu tangkai. Susunan buah dan bunga di tangkai memanjang tegak lurus dengan panjang 50$70 \mathrm{~cm}$ dan bunga berwarna putih kekuningan.

Tabel 1. Analisis vegetasi tumbuhan tingkat pohon

\begin{tabular}{c|c|c|c|c|c|c|c}
\hline No. & Spesies & Famili & $\begin{array}{c}\text { KR } \\
(\%)\end{array}$ & $\begin{array}{c}\text { FR } \\
(\%)\end{array}$ & $\begin{array}{c}\text { DR } \\
(\%)\end{array}$ & $\begin{array}{c}\text { INP } \\
(\%)\end{array}$ & $\begin{array}{c}\text { Pi In } \\
\text { pi }\end{array}$ \\
\hline 1. & Mallotus paniculatus Mull. Arg. & Euphorbiaceae & 66.67 & 50 & 64.81 & 181.48 & 0.30 \\
\hline 2. & Psychotria puncata Vatke & Rubiaceae & 33.33 & 50 & 35.19 & 118.52 & 0.37 \\
\hline \multicolumn{2}{r}{ Jumlah } & 100 & 100 & 100 & 300 & $\begin{array}{c}H^{\prime}= \\
0.67\end{array}$ \\
\hline
\end{tabular}

Tabel 2. Analisis vegetasi tumbuhan tingkat tiang

\begin{tabular}{cllccccc}
\hline No. & \multicolumn{1}{c}{ Spesies } & Famili & $\begin{array}{c}\text { KR } \\
(\%)\end{array}$ & $\begin{array}{c}\text { FR } \\
(\%)\end{array}$ & $\begin{array}{c}\text { DR } \\
(\%)\end{array}$ & $\begin{array}{c}\text { INP } \\
(\%)\end{array}$ & Pi In pi \\
\hline 1. & $\begin{array}{l}\text { Elaeocarpus sphaericus } \\
\text { var. hayatae }\end{array}$ & Elaeocarpaceae & 57.14 & 25 & 39.50 & 121.65 & 0.37 \\
\hline 2. & $\begin{array}{l}\text { Pandanus sarasinorum } \\
\text { Warb. }\end{array}$ & Pandanaceae & 14.28 & 50 & 32.53 & 96.82 & 0.36 \\
\hline 3. & Ficus virens Aiton & Moraceae & 28.58 & 25 & 27.97 & 81.53 & 0.35 \\
\hline & & 100 & 100 & 100 & 300 & $\begin{array}{l}\mathrm{H}^{\prime}= \\
1.08\end{array}$ \\
\hline
\end{tabular}

Tabel 3. Analisis vegetasi tumbuhan tingkat pancang

\begin{tabular}{lllccccc}
\hline No. & Spesies & Famili & $\begin{array}{c}\text { KR } \\
(\%)\end{array}$ & $\begin{array}{c}\text { FR } \\
(\%)\end{array}$ & $\begin{array}{c}\text { DR } \\
(\%)\end{array}$ & $\begin{array}{c}\text { INP } \\
(\%)\end{array}$ & Pi In pi \\
\hline 1. & Vaccinium $s p$. & Ericaceae & 50 & 33.34 & 44.74 & 128.06 & 0.37 \\
\hline 2. Melastoma malabathricum & L. & Melastomataceae & 30 & 33.33 & 36.31 & 99.64 & 0.36 \\
\hline 3. & Medinilla cumingii Naudin & Melastomataceae & 20 & 33.33 & 18.95 & 72.30 & 0.34 \\
\hline & & 100 & 100 & 100 & 300 & $\begin{array}{l}H^{\prime}= \\
1.07\end{array}$ \\
\hline
\end{tabular}

Tabel 4. Analisis vegetasi tumbuhan bawah

\begin{tabular}{cllrrrr}
\hline No. & \multicolumn{1}{c}{ Spesies } & \multicolumn{1}{c}{ Famili } & $\begin{array}{r}\text { KR } \\
(\%)\end{array}$ & $\begin{array}{r}\text { FR } \\
(\%)\end{array}$ & $\begin{array}{r}\text { INP } \\
(\%)\end{array}$ & Pi In pi \\
\hline 1. & Ageratum conyzoides L. & Asteraceae & 10.41 & 16.66 & 27.08 & 0.27 \\
\hline 2. & Begonia aptera Blume & Begoniaceae & 14.58 & 11.11 & 25.69 & 0.26 \\
\hline 3. & Asplenium amboinense Willd. & Aspleniaceae & 12.5 & 11.11 & 23.61 & 0.25 \\
\hline 4. & Pteridium aquilinum L. & Dennstaedtiaceae & 6.25 & 16.66 & 22.92 & 0.24 \\
\hline 5. & Coix lacryma-jobi l. & Poaceae & 16.67 & 5.56 & 22.22 & 0.25 \\
\hline
\end{tabular}


Rusmin, dkk. Biocelebes. Agustus. 2020. Vol. 14 No. 2, 177-186

\begin{tabular}{clllllc}
\hline 6. & Spathoglottis plicata Blume & Orchidaceae & 4.17 & 16.66 & 20.83 & 0.24 \\
\hline 7. & Bidens pilosa L. & Asteraceae & 14.58 & 5.56 & 20.14 & 0.23 \\
\hline 8. & Tridax procumbens L. & Asteraceae & 12.5 & 5.56 & 18.06 & 0.22 \\
\hline 9. & Clerodendrum $s p$. & Lamiaceae & 4.17 & 5.56 & 9.73 & 0.14 \\
\hline 10. & Rubus fraxinifolius Poir & Rosaceae & 4.17 & 5.56 & 9.72 & 0.15 \\
\hline \multicolumn{2}{r}{ Jumlah } & & 100 & 100 & 200 & $\mathrm{H}^{\prime}=2.23$ \\
\hline
\end{tabular}

Tabel 5. Kondisi suhu udara, kelembaban udara dan intensitas cahaya

\begin{tabular}{ccccc}
\hline No. & Waktu & Suhu $\left({ }^{\circ} \mathrm{C}\right)$ & Kelembaban $(\%$ rh) & Cahaya (lux) \\
\hline 1 & 05.00 & 16.84 & 73.16 & - \\
\hline 2 & 07.00 & 18.12 & 81.74 & 372.2 \\
\hline 3 & 12.00 & 27.18 & 59.62 & 581.46 \\
\hline 4 & 16.00 & 26.8 & 63.42 & 208.24 \\
\hline 5 & 19.00 & 23 & 72.86 & - \\
\hline \multicolumn{2}{c}{ Rata-rata } & 22.38 & 70.16 & 387.3 \\
\hline
\end{tabular}

Tabel 6. Kondisi pH dan kelembaban tanah di lokasi penelitian

\begin{tabular}{cccc}
\hline NO. & Plot & $\mathrm{pH}$ & Kelembaban (\%) \\
\hline 1 & $\mathrm{I}$ & 4.8 & 75 \\
\hline 2 & $\mathrm{II}$ & 5.2 & 55 \\
\hline 3 & $\mathrm{III}$ & 5 & 60 \\
\hline 4 & $\mathrm{IV}$ & 6.2 & 30 \\
\hline 5 & $\mathrm{~V}$ & 6 & 35 \\
\hline & Rata-rata & 5.44 & 51 \\
\hline
\end{tabular}

\section{PEMBAHASAN}

Jenis tumbuhan tingkatan pohon (DBH $>20 \mathrm{~cm}$ ) yang berada di sekitar Alpinia eremochlamys K.Schum. ada 2 jenis tumbuhan, dengan jenis yang dominan berdasarkan nilai INP tertinggi, yaitu Mallotus paniculatus Mull.Arg. dan yang terendah adalah Psychotria puncata (tabel 1), suku Euphorbiaceae dengan jenis $M$. panniculatus memperoleh INP tertinggi yaitu $181.48 \%$, sedangkan suku Rubiaceae dengan jenis Psychotria puncata memperoleh INP terendah yaitu $118.52 \%$.
Hal ini menunjukan bahwa keberadaan $M$. panniculatus suku Euphorbiaceae dapat berasosiasi dengan $A$. eremochlamys K.Schum., karena tumbuhan ini dapat bertoleransi dengan kondisi lingkungan di sekitar area lokasi penelitian yang merupakan hutan pegunungan yang memiliki suhu udara rendah dan kelembaban udara yang tergolong tinggi sehingga jumlah individu dari jenis tumbuhan ini semakin besar.

Menurut Maisyaroh (2010), faktor lingkungan berperan sangat penting dalam 
berlangsungnya kehidupan tumbuhan seperti suhu, kelembaban dan intensitas cahaya yang merupakan iklim mikro yang mempengaruhi pertumbuhan dan mewujudkan keadaan lingkungan optimal. Semakin tinggi suatu tempat biasanya berasosiasi dengan peningkatan kelembaban udara dan penurunan suhu sehingga mengakibatkan suatu komunitas tumbuh homogen.

Pada tingkatan tiang (DBH $10-20 \mathrm{~cm})$ ada 3 jenis tumbuhan, dengan jenis yang dominan berdasarkan nilai INP tertinggi, yaitu suku Elaeocarpaceae dengan jenis Elaeocarpus sphaericus var. hayatae $121.65 \%$ dan yang terendah yaitu suku Moraceae dengan jenisFicus virens Aiton $81.53 \%$ (tabel 2). Hal ini menunjukan bahwa keberadaan $E$. sphaericus var. hayatae dapat berasosiasi dengan $A$. eremochlamys K.Schum., karena tumbuhan ini mempunyai produktivitas yang besar dan mampu beradaptasi pada hutan dengan ketinggian 600-2.000 m dpl (Van Steenis, 2010).

Pada tingkatan pancang $(\mathrm{DBH}<10 \mathrm{~cm})$ ada 3 jenis tumbuhan, dengan jenis yang dominan berdasarkan nilai INP tertinggi, yaitu suku Ericaceae dengan jenis Vaccinium sp. $128.06 \%$ dan terendah yaitusuku Melastomataceae dengan jenisMedinilla cumingii Naudin $128.06 \%$ (tabel 3). Hal ini dikarenakan jenis tumbuhan ini merupakan jenis tumbuhan yang mampu menguasai tempat tumbuh dan berkembang sesuai kondisi lingkungannya secara keseluruhan atau sebagian besar berada pada tingkat yang paling atas dari semua jenis yang berada pada suatu komunitas vegetasi.

Pada tingkatan tumbuhan bawah adalah komunitas tumbuhan penyusun stratifikasi bawah dekat permukaan tanh. Tumbuhan ini umumnya berupa rumput, herba, semak atau perdu rendah. Secara taksonomi vegetasi bawah umumnya dari anggota suku-suku Poaceae, Cyperaceae, Araceae, Asteraceae dan kerabat paku-pakuan. Vegetasi ini banayak terdapat di tempattempat terbuka, tepi jalan, tebing sungai, lahan pertanian dan perkebunan (Aththorik, 2005). Dari hasil penelitian yang dilakukan, di temukan sebanyak 10 jenis tumbuhan dari 8 suku (tabel 4), yang mana jenis tumbuhan yang memiliki INP teringgi adalah Ageratum conyzoides L. (Asteraceae) yaitu $22.22 \%$ dan jenis tumbuhan yang memiliki INP terendah adalah Rubus fraxinifolius Poir (Rosaceae) yaitu $9.72 \%$. Jenis tumbuhan tingkatan bawah ini didominansi oleh Ageratum conyzoides L., jenis ini merupakan jenis dari suku Asteraceae yang berasal dari daerah tropis di Amerika. Famili Asteraceae ditemukan dalam jumlah banyak dikarenakan keanekaragaman spesies dari tumbuhan ini cukup tinggi.

Presentase jenis tumbuhan berdasarkan tingkat pertumbuhan di sekitar Alpinia eremochlamys K.Schum. didominasi pada 
tingkat tumbuhan bawah dengan presentase sebesar $55 \%$, diikuti oleh tingkat pancang sebesar $17 \%$, tingkat tiang sebesar $17 \%$ dan pada tingkat pohon $11 \%$ (Gambar 7). Hal ini menunjukkan bahwa kehadiran tumbuhan bawah dalam suatu kawasan hutan mempunyai peranan yang sangat penting dan juga pada lokasi penelitian, spesies pohon tidak terlalu banyak di daerah tersebut, sehingga matahari cukup baik pada kawasan ini.

Alpinia eremochlamys K.Schum. tumbuh subur di daerah hutan hujan pegunungan (pegunungan yang lembab), keadaan topografi area tempat tumbuh $A$. eremochlamys K.Schum. pada hutan Pegunungan sekitar Danau Kalimpa'a termasuk berbukit sampai curam berbukit dan terletak pada ketinggian 1600-1800 m dpl. Suhu udara pada lokasi penelitian $A$. eremochlamys K.Schum. berkisar antara $16.84{ }^{\circ} \mathrm{C}$ (05.00 WITA) sampai $27.18{ }^{\circ} \mathrm{C}$ (12.00 WITA) dengan suhu rata-rata 22.38 ${ }^{\circ} \mathrm{C}$. Untuk kelembaban relatif (Rh) berkisar antara $59.62 \%-81.74 \%$ dengan rata-rata $70.16 \%$. Untuk intensitas cahaya antara 372.2 lux (pukul 07.00 WITA pagi hari) hingga 581.46 lux (pukul 12.00 WITA siang hari) dengan rata-rata 387.3 lux (tabel 5). Suhu udara dan kelembaban udara merupakan faktor lingkungan yang sangat berpengaruh terhadap pertumbuhan suatu vegetasi pada habitatnya. Kelembaban dan suhu udara merupakan komponen yang sangat mempengaruhi pertumbuhan tanaman dan masing-masing berkaitan mewujudkan keadaan lingkungan optimal bagi tanaman. Intensitas cahaya dapat mempengaruhi proses metabolisme pada tanaman. Intensitas cahaya rendah pada umumnya disebabkan oleh naungan (Ardie, 2006). Hasil pengukuran $\mathrm{pH}$ dan kelembaban tanah pada plot 1 yaitu $\mathrm{pH} 4.8$ dengan kelembaban $75 \%$, plot 2 yaitu $\mathrm{pH}$ 5.2 dengan kelembaban $55 \%$, plot 3 yaitu $\mathrm{pH} 5$ dengan kelembaban $60 \%$, plot 4 yaitu pH 6.6 dengan kelembaban $30 \%$ dan plot 5 pH 6 dengan kelembaban 35\%. Secara keseluruhan dari tiap plot, diperoleh ratarata $\mathrm{pH}$ yaitu 5.44 dengan kelembaban yaitu $51 \%$. Berdasarkan kondisi tersebut, menunjukkan vegetasi tumbuhan disekitar Alpinia eremochlamys K.Schum. lebih toleran sehingga mampu tumbuh dengan baik.

\section{SIMPULAN}

Berdasarkan hasil penelitian dapat disimpulkan bahwa jenis-jenis vegetasi yang berasosiasi pada habitat Alpinia eremochlamys K.Schum. yaitu diperoleh vegetasi tingkat pohon didominasi dari suku Euphorbiaceae jenis Mallotus paniculatus Mull.Arg. dengan INP 181.48\%, vegetasi tingkat tiang dari suku Elaeocarpaceae jenis Elaeocarpus sphaericus var. hayatae dengan INP $121.65 \%$, vegetasi tingkat pancang dari suku Ericaceae dengan jenis Vaccinium $s p$. dengan INP $128.06 \%$ dan 
vegetasi tingkat tumbuhan bawah dari suku Asteraceaejenis Ageratum conyzoides L. yaitu $22.22 \%$.

\section{DAFTAR PUSTAKA}

Aththorick. T. A. 2005. Kemiripan Komunitas Tumbuhan Bawah pada Beberapa Tippe Ekosistem Prkebunan di Kabupaten Labuhan Batu. Komunikasi Penelitian, 17(5), 1.

Ardie. W. S. 2006. Pengaruh Intensitas Cahaya dan Pemupukan terhadap Pertumbuhan dan Pembungaan Hoya diversifolia Blume. Bogor: Sekolah Pasca Sarjana, Institut Pertanian Bogor.

Kementrian Lingkungan Hidup dan Kehutanan. 2015. BIOSFER. Berita, Informasi, Opini, eni, Fkata, Edukasi dan Ruang Kreasi. Palu: Balai Besar Taman Nasional Lore Lindu.

Lee, R. J., Riley, J., dan Merrill, R. 2001. Keanekaragaman Hayati dan Konservasi Di Sulawesi Bagian Utara. Jakarta: WCS-IP dan NRM.
Maisyaroh, W. 2010. Struktur Komunitas Tumbuhan Penutup Tanah di Taman Hutan Raya R. Soerjo Cangar Malang. Pembbangunan dan Alam Lestari, 1(1), 20-22.

Pitopang, R. 2012. Struktur Dan Komposisi Vegetasi Pada 3 Zona Elevasi Yang Berbeda Di Taman Nasional Lore Lindu Sulawesi Tengah Indonesia. Natural Science, 1(1),85-105.

Pitopang, R., Lapanjang, I., dan Burhanuddin, I. 2011. Profil Herbarium Celebense dan Deskripsi 100 Jenis Pohon Sulawesi. Editor : Basri Z. Palu: Universitas Tadulako Press.

Santika, Y. 2015. Keanekaragaman ZingiberaceaePulau Wawoni Sulawesi Tenggara.Prosiding Seminar Nasional Penelitian dan PKM Sains dan Teknologi, 5(1), 9-14.

Van Steenis, C, G, G. 2010. Flora Pegunungan Jawa. Pusat Peneliti Biologi LIPI. Bogor, Indonesia, 71b:817. 